\title{
CONTAMINAÇÃO DAS ÁGUAS SUBTERRÂNEAS POR LIXÕES DESATIVADOS: AVALIAÇÃO DA ANTIGA ÁREA DE DISPOSIÇÃO FINAL DE RESÍDUOS SÓLIDOS DE ROLÂNDIA - PR
}

\author{
Monielen Monara Betio ${ }^{1}$; Maurício Moreira dos Santos ${ }^{2}$
}

\begin{abstract}
Resumo - A área pesquisada refere-se ao antigo lixão de Rolândia, antes de sua desativação, no ano de 2003, a área de estudo foi o destino final da coleta pública de resíduos sólidos do município durante décadas. Os resíduos eram depositados diretamente ao solo sem proteção, expondo a massa a ação direta da chuva e ao processo de decomposição. Dessa maneira, a infiltração do percolado através da zona não saturada do solo pode influenciar na contaminação de aquíferos, produzindo uma pluma cujo fluxo é a base dos rios. Tem-se como objetivo, avaliar os impactos ambientais causados pela massa aterrada de resíduos sólidos sobre a qualidade das águas subterrâneas, analisando, para esse fim, parâmetros hidroquímicos - potencial Hidrogeniônico (pH), Condutividade Elétrica (CE), turbidez, Nitrito $\left(\mathrm{NO}_{2}{ }^{-}\right)$, Nitrato $\left(\mathrm{NO}_{3}{ }^{-}\right)$e Chumbo. Foram coletadas amostras de água em três poços de monitoramento (P1, P2 e P3), instalados entre o talude de massa aterrada e o ribeirão Vermelho, realizadas duas campanhas para coleta, sendo a primeira realizada em 04 de Outubro e a segunda, em 10 de Novembro de 2014. Os resultados das análises físicoquímicas comprovaram que a água subterrânea nos poços são impróprias para consumo humano, comparando aos padrões legislativos.
\end{abstract}

\begin{abstract}
The research area is the old garbage dump of Rolândia city, before its deactivation, in 2003, the study area was the final destination of the public solid waste collection in the city for decades. The waste was deposited directly into the soil unprotected, exposing the mass direct action of the rain and the decomposition process. In this way, the percolated infiltration through unsaturated soil may influence contamination of aquifers, producing a plume which flow is the basis of the rivers. It has been the objective, to evaluate the environmental impacts caused by the waste mass buried on groundwater quality, analyzing, for this purpose, hydrochemical parameters Hydrogen potential, Electric Conductivity, turbidity, Nitrite, Nitrate and Lead. Water samples were collected in three monitoring wells (P1, P2 and P3), installed between mass buried slope and Red brook, conducted two campaigns to collect, the first was held on 04 October and the second on November 10, 2014. The physicochemical analysis results proved that groundwater in wells are improper for human consumption, comparing the legislative standards.
\end{abstract}

Palavras-Chave - Nitrito, Nitrato, Chumbo.

\footnotetext{
${ }^{1}$ Graduada em Engenharia Ambiental pela Universidade Tecnológica Federal do Paraná - campus Londrina, monielenmonara@gmail.com ${ }^{2}$ Professor Dr.da Universidade Tecnológica Federal do Paraná - Campus Londrina, Av. dos Pioneiros, 3131, CEP 86036-370 - Londrina - PR Brasil,mmsantos@utfpr.edu.br
} 


\section{1 - INTRODUÇÃO}

Os resíduos sólidos urbanos depois de passarem pelo processo de coleta, transporte e acondicionamento, necessitam de um local para ser disposto. Esses locais, dependendo de suas características geotécnicas e construtivas, podem ser classificados como aterros sanitários, quando existem sistemas de proteção contra a poluição dos solos e corpos d'água ou lixões, quando a ausência dessa proteção trazem riscos para poluição dos solos, ar e águas.

O surgimento dos lixões em grandes e pequenas cidades está ligado a falta de conhecimento técnico e de investimentos em soluções voltadas à problemática dos resíduos sólidos. Vale ainda ressaltar que os lixões ou vazadouros a céu aberto são desprovidos de quaisquer critérios técnicocientíficos e ecológicos de manejo, sendo consideradas áreas totalmente inaptas ao controle dos poluentes gerados pelo processo de decomposição da matéria orgânica tornando-se fontes potenciais de contaminação, gerando riscos ao meio ambiente e em particular para a qualidade dos solos, águas superficiais e subterrâneas.

A água subterrânea, uma vez contaminada, principalmente por substâncias tóxicas e persistentes, tem sua remediação e recuperação, condições técnicas e econômicas impraticáveis, pois, uma vez existente fonte de contaminação, liberando os seus produtos para a zona saturada, o fluxo das águas subterrâneas os transporta através de correntes advectivas ao longo de seu deslocamento, gerando-se assim uma pluma de contaminação (SANTOS, 2003).

Dessa forma, trabalhos que visem a aplicação de métodos de investigação e monitoramento para avaliar impactos ambientais em áreas de lixões (ativados ou desativados) são de suma importância para a compreensão dos processos ambientais. Principalmente, envolvendo condicionantes hidrogeológicos e hidroquímicos de aquíferos freáticos e das águas superficiais em áreas de influência, como ocorre no antigo lixão de Rolândia-PR, local objeto de estudo da presente pesquisa.

Cabe ressaltar, diante da nova Política Nacional de Resíduos Sólidos, todos os lixões municipais devem ser encerrados, e cenário, como esse apresentado no presente artigo, prestam como alerta à condição de contínua deterioração da qualidade das águas subterrâneas e superficiais, mesmo após vários anos de desativação da área de disposição, inserindo o contexto, com base aos fatos, para o contínuo monitoramento dessas áreas, mesmo após sua desativação. 


\section{2 - OBJETIVOS}

O objetivo desta pesquisa é de avaliar os impactos ambientais causados pela massa aterrada de resíduos sólidos do lixão desativado no município de Rolândia - PR sobre a qualidade das águas subterrâneas, analisando, para esse fim, alguns parâmetros hidroquímicos: $\mathrm{pH}$, Condutividade Elétrica (CE), turbidez, Nitrito $\left(\mathrm{NO}_{2}{ }^{-}\right)$e Nitrato $\left(\mathrm{NO}_{3}{ }^{-}\right)$, e Chumbo.

\section{3 - CARACTERIZAÇÃO DA ÁREA DE ESTUDO}

A área total do município de Rolândia compreende $467,31 \mathrm{~km}^{2}$, altitude média de 730 metros. Tem como coordenadas geográficas no centro da cidade: Latitude $23^{\circ} 19^{\prime} 00^{\prime \prime}$ Sul e Longitude $51^{\circ} 22^{\prime} 00^{\prime}$ ' Oeste. A área de pesquisa localiza-se no perímetro urbano da cidade mais precisamente na porção norte do município. O local de estudo foi durante 60 anos o destino final da coleta pública de resíduos sólidos urbanos do município, antes de sua desativação em abril de 2002. Possui área total de $65.318 \mathrm{~m}^{2}$, área efetiva com lixo de cerca de $30.318 \mathrm{~m}^{2}$ e com volume estimado de capacidade de $180.000 \mathrm{~m}^{3}$ de lixo depositado. Localizada na bacia hidrográfica do ribeirão Vermelho, na vertente esquerda se distancia em $2 \mathrm{~km}$ da sua nascente (Figura 1).
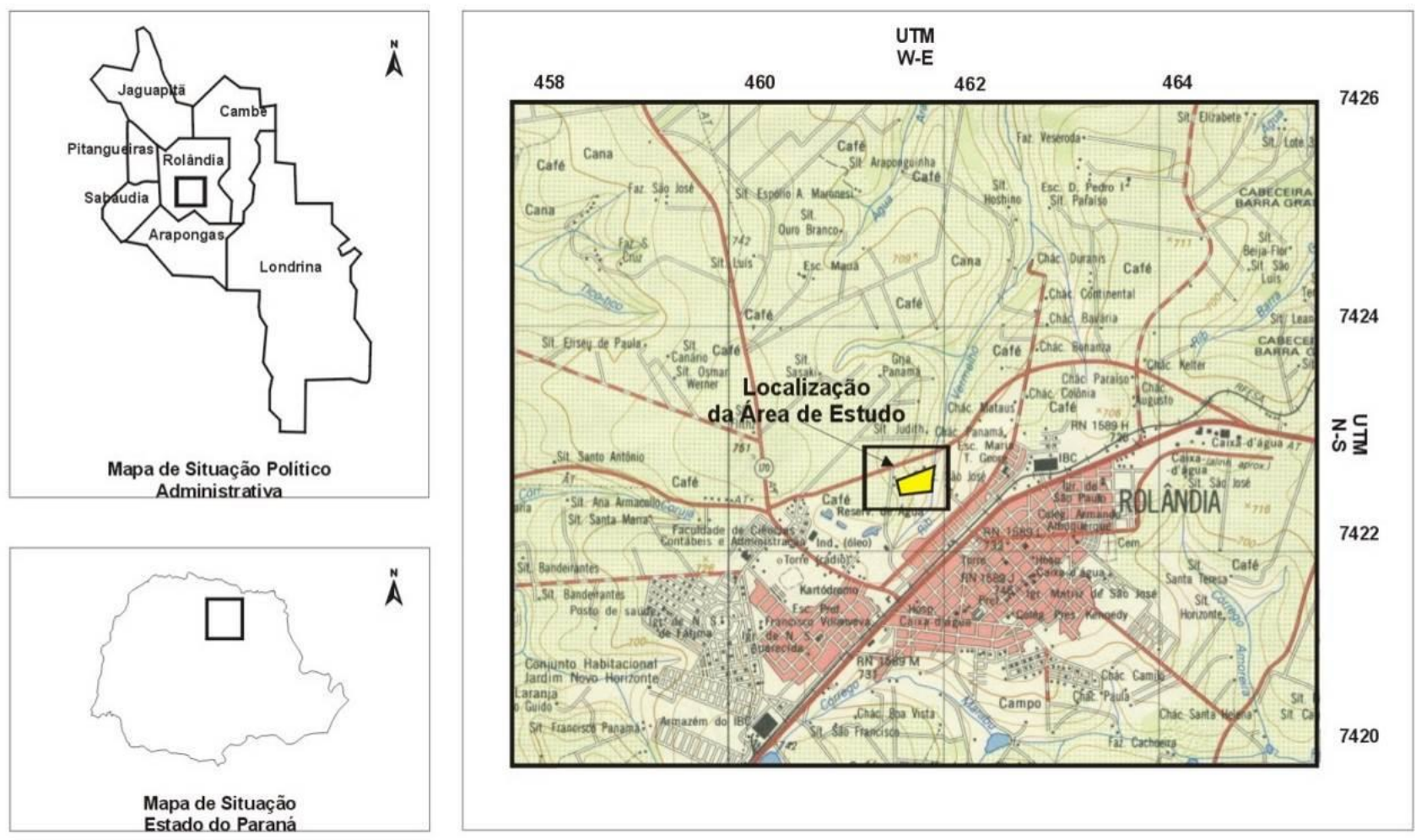

Figura 1. Mapa de localização do antigo lixão de Rolândia - PR. Fonte: Santos (2003). 
O estado do Paraná possui influência macroclimática de predominância subtropical, na zona em questão destacam-se os subtipos climáticos: Cfa (Subtropical Úmido Mesotérmico); Cfb (Subtropical Super-Úmido Mesotérmico); Af (Clima Tropical Super-Úmido); e Cwa, que se diferencia da Cfa pelo fato de apresentar estiagem no inverno.

O norte paranaense, no qual envolve a área de estudo, possui evolução geomorfológica disposta por toda a bacia sedimentar do Paraná, inserida no Terceiro Planalto Paranaense, onde se desenvolve a estrutura geomorfológica das Cuestas Areníticas Basálticas (SANTOS, 2003).

Na região do antigo lixão de Rolândia o relevo é ondulado a suavemente ondulado, com vales pouco entalhados e vertentes longas e com baixa declividade (Figura 2). Com cotas topográficas variando entre 660 e 720 metros acima do nível do mar, a conformação topográfica da área de estudo possui inclinação suave no sentido W-E, obedecendo à drenagem do Ribeirão Vermelho, cujo sentido SW-NE obedece por sua vez, a drenagem do rio Paranapanema, do qual é afluente direto, constituindo ambos parte da Bacia do Rio Paraná (SANTOS, 2003).

O Latossolo Vermelho e o Nitossolo são as principais formações pedológicas encontradas na região do município. De modo geral, os solos na região em questão apresentam-se normalmente profundos, pouco suscetíveis à erosão. Suas características morfológicas apresentam poucas variações, fazendo com que os diversos horizontes se apresentem poucos individualizados e difusos. O Latossolo Vermelho é formado quase que completamente da rocha mãe (basalto) e constituído de grandes quantidades de ferro hidratado, dando-lhe a característica de coloração bastante escura (SANTOS, 2003).

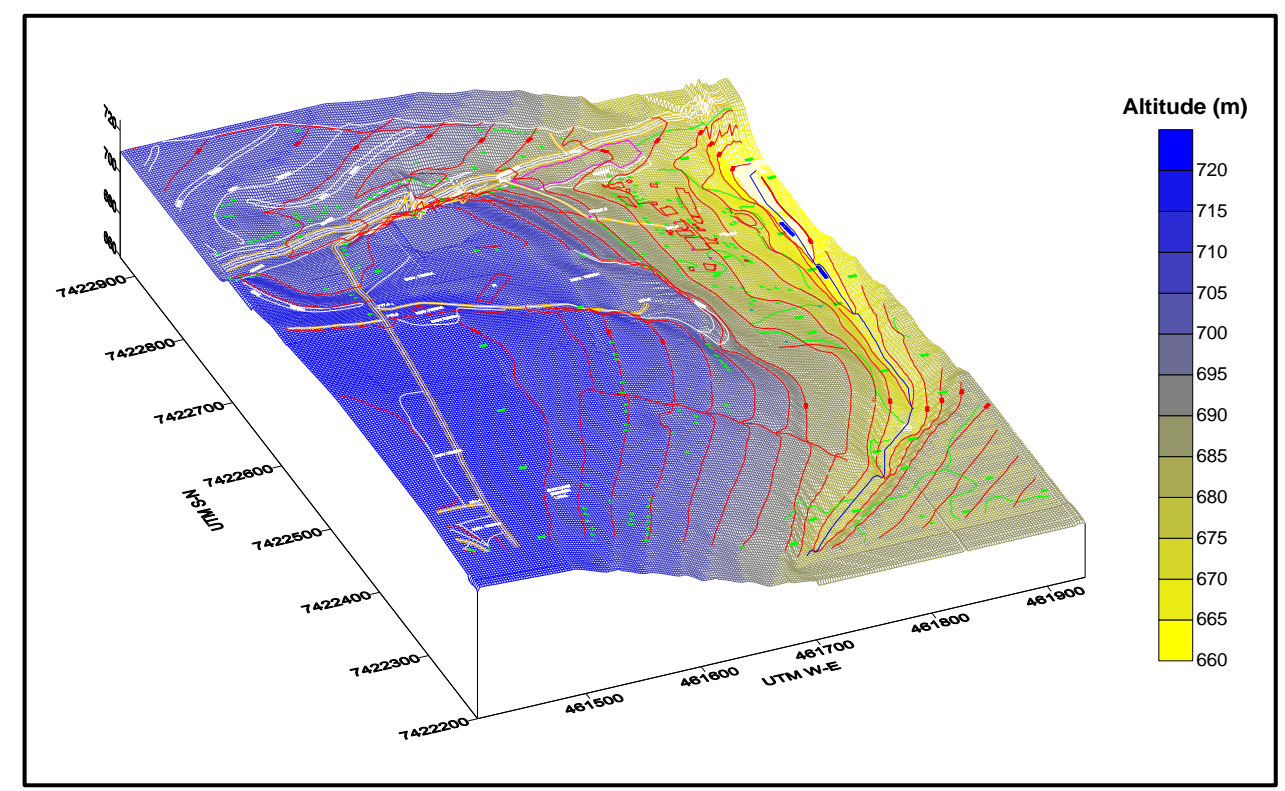

Figura 2. Bloco diagrama evidenciando a conformação topográfica da área de estudo. Fonte: Santos (2003). 
A área de estudo está inserida geologicamente nos limites da Bacia Sedimentar do Paraná, assentada sobre os basaltos pertencentes a Formação Serra Geral, que têm origens do intenso vulcanismo fissural que atingiu a bacia, constituindo ampla província magmática, definindo no Fanerozóico a maior manifestação ígnea não-oceânica e uma importante contribuição à geração da crosta ocidental do planeta. Esse evento traduziu-se na bacia, como uma espessa cobertura de lavas, uma intricada rede de diques contando a completa seção sedimentar.

Segundo Milani (1997) a Formação Serra Geral, de maneira generalizada, é composta principalmente por rochas vulcânicas básicas, toleíticas e andesitos basálticos ocorrendo subordinadas quantidades de riodacitos e riolitos, de textura afanítica, coloração cinza e negra. Os topos dos derrames é geralmente amigdaloidal, apresentando grande desenvolvimento de juntas verticais e horizontais com intrusões alcalinas e de pequenas lentes de arenito (MILANI, 1997).

\section{1 - Hidrogeologia}

$\mathrm{Na}$ área estudada existem duas formas de ocorrência de água subterrânea: o aquífero freático e o sistema aquífero Serra Geral (CELLIGOI et al., 2001).

O aquífero freático tem características essenciais de aquífero livre ou não confinado. Visto que possui camadas de solo e rocha alterada e é formado por sedimentos argilosos, constituindo-se em um meio poroso heterogêneo, geralmente pouco espesso e com baixa profundidade do nível saturado. Dessa forma, a recarga se dá diretamente a partir de águas pluviais nas áreas mais elevadas topograficamente, aumentando os riscos em relação à contaminação ou poluição das águas subterrâneas (SANTOS, 2003).

A superfície freática do local acompanha de uma forma geral a superfície do terreno evidenciada. A Figura 3 demonstra uma conformação topográfica cuja área de recarga local do aquífero freático se encontra nas porções mais elevadas do terreno, sendo a área de descarga localizada nas partes mais rebaixadas do relevo, em direção à calha do ribeirão Vermelho (SANTOS, 2003) 


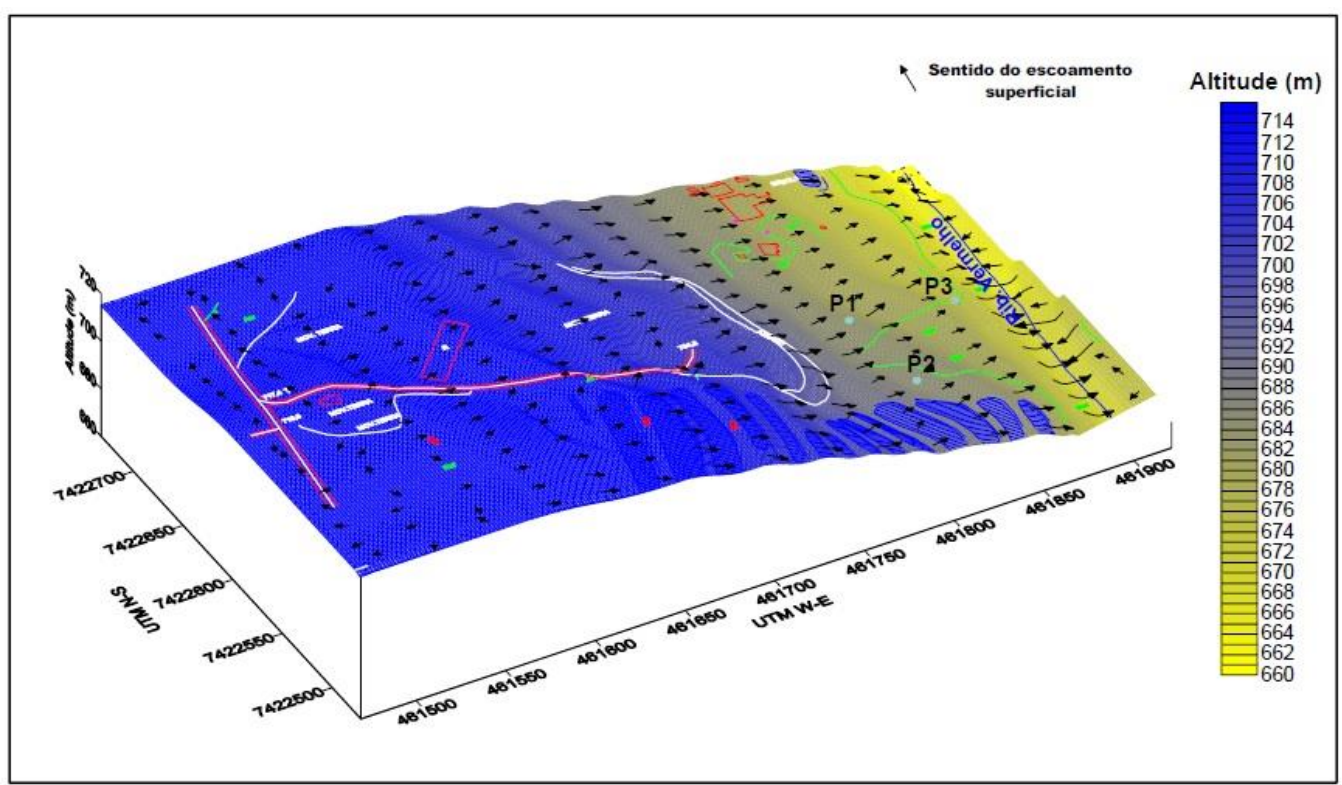

Figura 3. Bloco diagrama evidenciando a conformação topográfica, área de recarga e descarga do aquífero da área estudada. Fonte: Santos (2003).

\section{4 - METODOLOGIA}

A avaliação hidroquímica foi realizada nas águas subterrâneas coletadas nos três poços e em um ponto de surgência natural, denominada $\mathrm{N}$, localizada a cerca de $2 \mathrm{~km}$ de distância dos poços (Figura 4). Esta nascente serviu de base de referência de água como provável livre de contaminação, uma vez que, após analise in loco da área, apontou que o uso do solo no entorno e zona de recarga da surgência não acarreta riscos de contaminação para as águas subterrâneas e ainda, analisando o trabalho de Santos (2003), o qual indica que esta zona está fora do sentido do fluxo de água subterrânea que passa pela massa de resíduos aterrada no antigo lixão. 


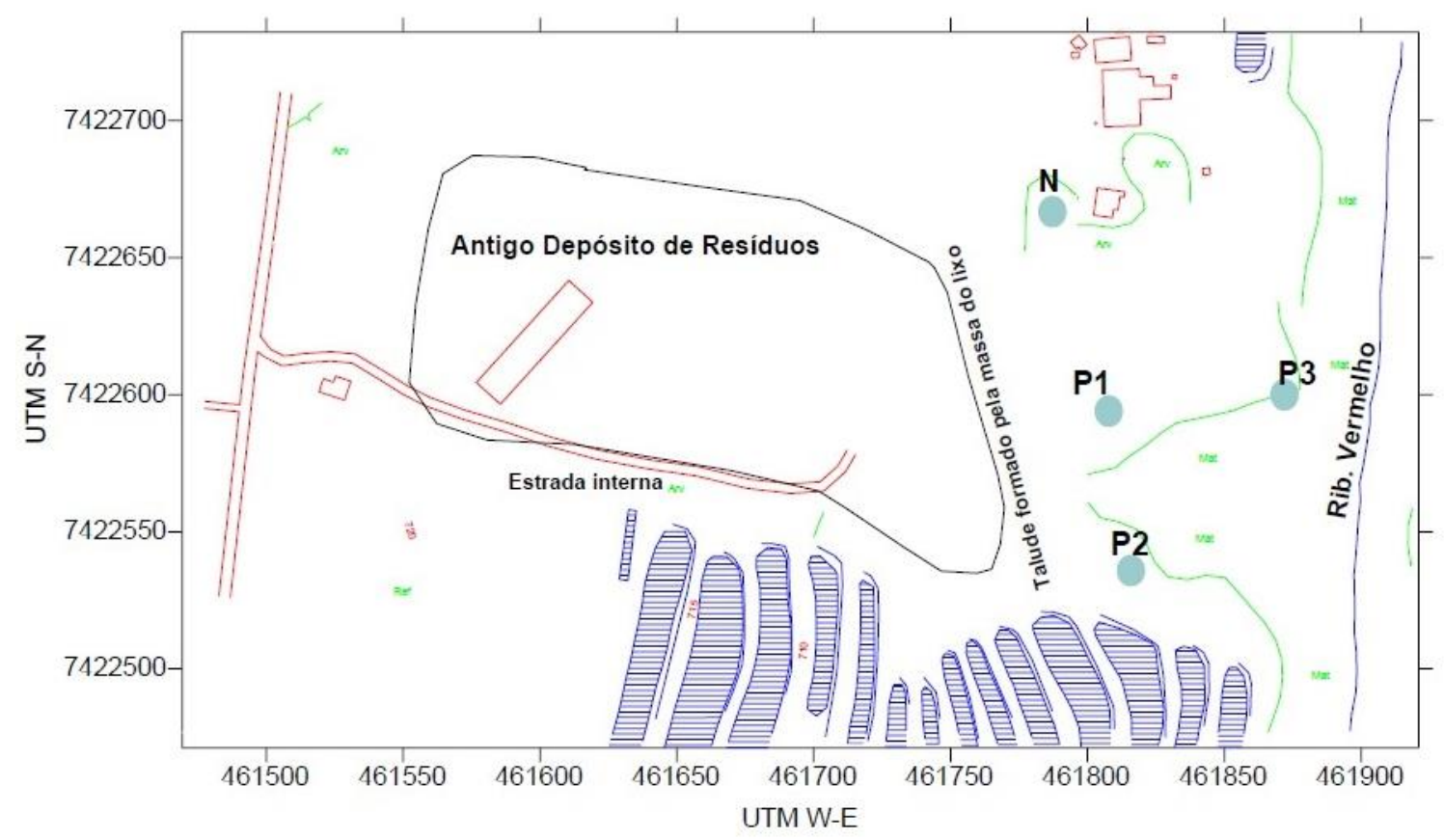

Figura 4 - Mapa de localização dos pontos de coleta de água. Fonte: Autor (2014).

\section{1 - Coleta das Amostras}

A água parada no poço pode não ser representativa da qualidade da água do local. Portanto, foi necessário remover a água estagnada no poço e no pré-filtro, de tal forma que a água de formação substitua a água estagnada (CETESB, 1999).

As amostras foram coletadas, armazenadas e transportadas seguindo as recomendações da norma CETESB 6410 de 1988 atualizada em 1999, adaptada da norma NBR 13.895 de Junho de 1997.

Primeiramente, os poços foram estagnados utilizando-se tubos coletores descartáveis de PVC tipo bailer, de diâmetro externo de $41 \mathrm{~mm}$, para, primeiramente o purgeamento ou esvaziamento e posterior coleta de água dos poços de monitoramento, possui comprimento de $95 \mathrm{~cm}$ e capacidade de 1,1 litros (Figura 5a).

Os poços P1 e P2 foram purgeados cerca de 20 vezes e o P3, 15 vezes para promover a recirculação da água no interior do poço. Ao remover a água estagnada dos poços é necessário esperar para recuperação do nível estático dos poços. Cabe destacar ainda, que todo o processo deve ser conduzido delicadamente para não haver alteração das propriedades físicas da água, especialmente a turbidez.

Após o retorno de água do aquífero, utilizando o bailer obtêm-se, então, as amostras de água, estas foram armazenadas em frascos plásticos de polietileno esterilizados, sendo um para cada poço, evitando a contaminação entre os poços (Figura 5b). Esses recipientes com as amostras d'água 
foram armazenados em bolsa térmica contendo gelo em cubos para resfriamento e conservação das propriedades físicas da água.
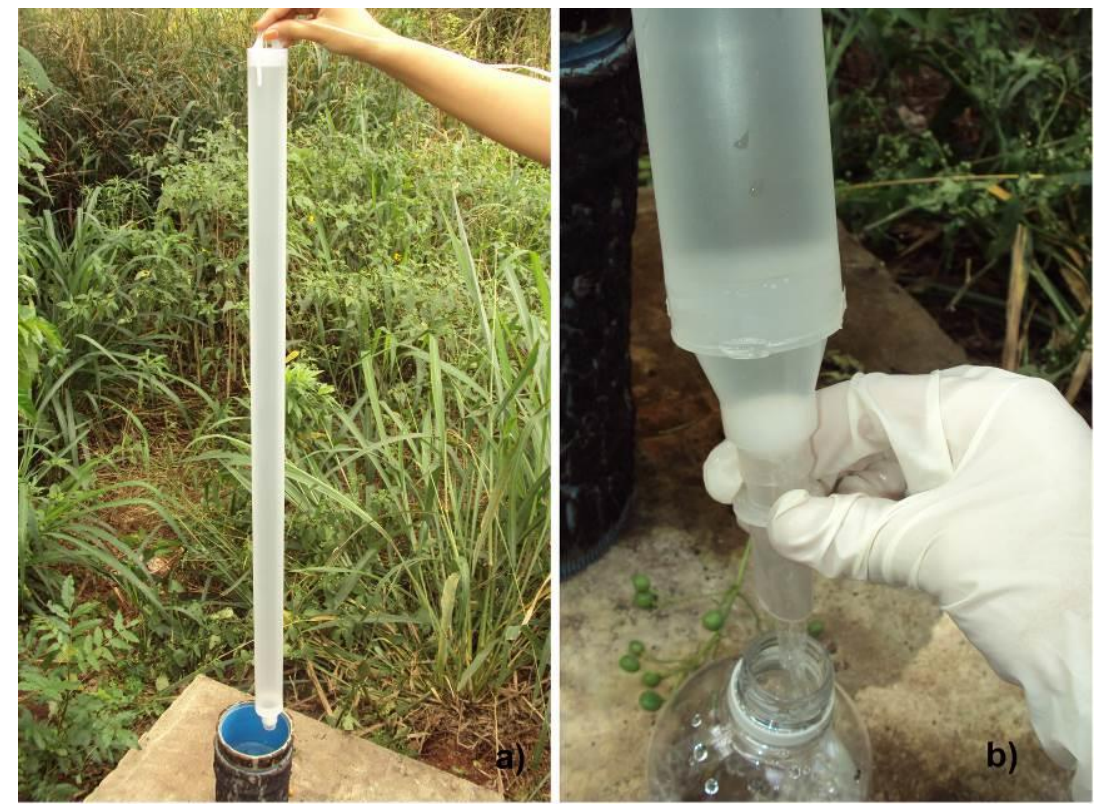

Figura 5 - a) Foto com bailer utilizado para purgeamento dos poços; b) Em destaque coleta da amostra d'água em recipientes plásticos para armazenamento temporário e transporte das amostras. Fonte: Autor (2014).

Foram realizadas 2 campanhas para coleta das amostras, sendo a primeira realizada em 04 de Outubro e a segunda, em 10 de Novembro de 2014. Na primeira data as amostras coletas foram encaminhadas para o Laboratório de Saneamento Ambiental da Universidade Tecnológica Federal do Paraná (UTFPR) campus Londrina. A segunda coleta foi realizada em duplicatas, sendo que, destas, uma amostra foi encaminhada para laboratório especializado para detecção do chumbo e a outra amostra foi para o Laboratório de Saneamento Ambiental da UTFPR campus Londrina. Todos os parâmetros analisados, de acordo com a data que foi realizada a coleta, estão evidenciados na Tabela 1.

Tabela 1 - Datas e parâmetros físico-químicos analisados.

\begin{tabular}{ccc}
\multirow{2}{*}{ Parâmetro } & \multicolumn{2}{c}{ Data } \\
\cline { 2 - 3 } & 04/out & $\mathbf{1 0 / n o v}$ \\
\hline \multirow{2}{*}{ Físico } & $\mathrm{pH}$ & $\mathrm{pH}$ \\
& $\mathrm{CE}$ & $\mathrm{CE}$ \\
& - & Turbidez \\
\hline \multirow{2}{*}{ Químico } & - & Nitrito \\
& - & Nitrato \\
& - & Chumbo $^{1}$ \\
\hline
\end{tabular}

Nota $^{1}$ : Amostra encaminhada para Laborsolo Laboratórios em Londrina-PR. 


\section{2 - Parâmetros}

Em todos os parâmetros, incluindo a detecção de chumbo realizada em laboratório especializado, as metodologias aplicadas seguem as especificações indicadas no Standard Methods Examination of Water and Wastewater (APHA, AWWA \& WEF, 2012).

$\mathrm{O} \mathrm{pH}$ foi medido diretamente na amostra, sem transferi-la para outro frasco para reduzir ao máximo as perdas por agitação e volatilização, após calibração do medidor de pH com solução tampão padrão. O equipamento utilizado foi o pHgâmetro de bancada da ION pH B500.

A Condutividade Elétrica também foi medida diretamente na amostra. O condutivímetro usado foi o de bancada, Thermo Scientific Orion 3 star Conductivity Benchtop, disponível no laboratório, após calibração com solução tampão.

Para a determinação da turbidez das amostras, estas foram colocadas em tubos específicos para o turbidímetro de bancada da marca Hach 2100 AN Turbidimeter, disponível no laboratório de saneamento.

Para a determinação do parâmetro Nitrito foi necessário diluir a amostra. A diluição feita foi de 1:10 em um balão volumétrico de $100 \mathrm{ml}$. Com uma pipeta volumétrica de $10 \mathrm{ml}$, colocou-se 9 $\mathrm{ml}$ da amostra diluída em tubos, adicionou-se 0,2 $\mathrm{ml}$ da solução de Sulfanilamida, com uma pipeta automática, seguido de agitação do tubo com tampa, deixando de repouso de 2 a 8 minutos. Após esse tempo, foi adicionado 0,2 $\mathrm{ml}$ de $\mathrm{N}$-(1-naftil)-etilenodiamino dihidroclorídrico, tampou-se e agitou-se imediatamente. $\mathrm{O}$ mesmo procedimento foi feito em um tubo contendo água destilada, como amostra em branco, sem Nitrito. A Figura 6 mostra os principais materiais utilizados na realização deste experimento. Primeiramente, foi realizada a leitura do tubo contento em branco, sem nitrito para "zerar" o equipamento. Posteriormente, leu-se as amostras. O equipamento para a leitura utilizado foi o Espectrofotômetro UV-Visível, marca HACH modelo DR500, no modo single wavelength com comprimento de onda $(\lambda)$ igual a $543 \mathrm{~nm}$. A leitura foi realizada em absorbância (Abs). Após a leitura, usou-se a equação da reta obtida através da curva de calibração. O resultado foi multiplicado por 10 . 


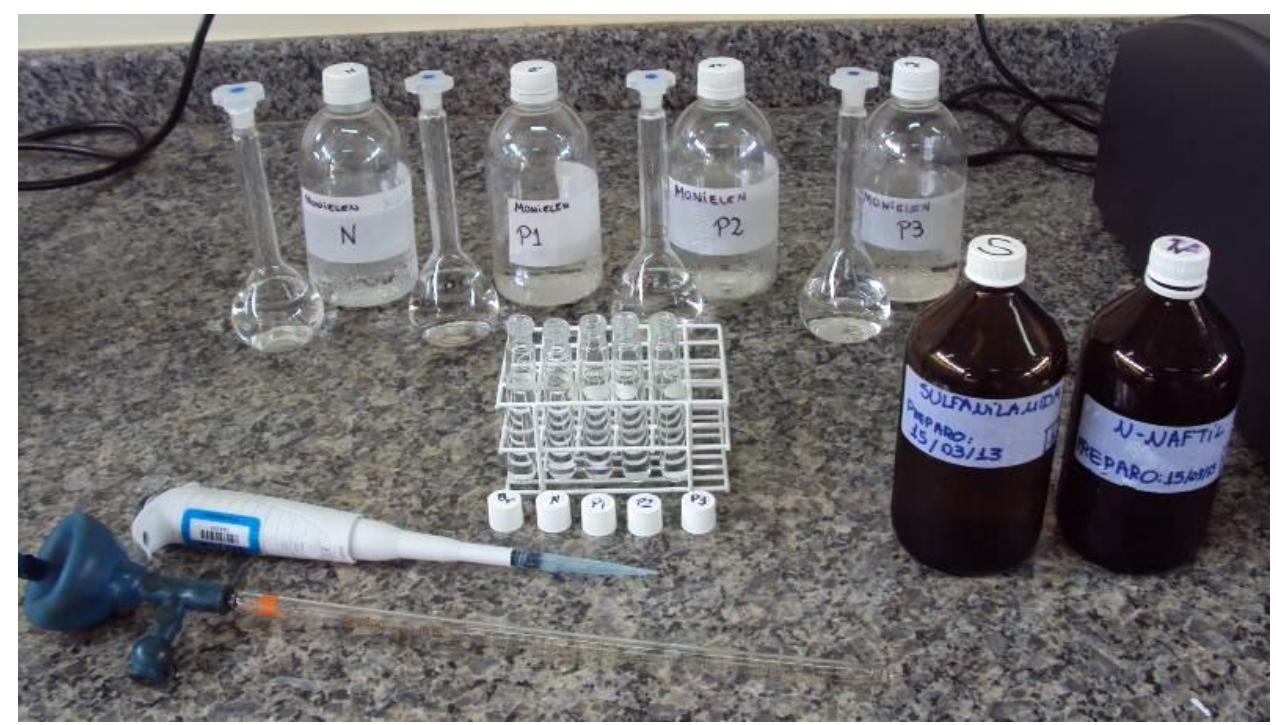

Figura 6 - Principais materiais utilizados na determinação do Nitrito.

Na determinação do Nitrato utilizou-se a mesma amostra usada na determinação do Nitrito diluída 1:10. Colocou-se a amostra diluída diretamente na cubeta de quartzo que foi inserida no Espectrofotômetro UV-Visível. Foram realizadas duas leituras em cada amostra, no modo single wavelength, com comprimento de onda ( $\lambda$ ) 220 e $275 \mathrm{~nm}$. O branco foi feito com a cubeta de quartzo contendo apenas água, que também foi lido nos dois comprimentos de onda para "zerar" o equipamento. A leitura feita com dois comprimentos de onda é necessário pois o $\lambda=220 \mathrm{~nm}$ faz a leitura da matéria orgânica e do nitrato na amostra, e o $\lambda=275 \mathrm{~nm}$ faz a leitura apenas da matéria orgânica. A leitura em $275 \mathrm{~nm}$ não deve exceder 10\% do valor lido em $220 \mathrm{~nm}$. Se isto ocorrer, significa que a matéria orgânica não foi totalmente removida.

Por esse motivo, o cálculo da absorbância do Nitrato foi feito da seguinte forma:

$$
\text { Absorbância } \mathrm{NO}_{3}=(\text { absorbância } 220 \mathrm{~nm})-2 x(\text { absorbância } 275 \mathrm{~nm})
$$

Após a correção da determinação da absorbância do Nitrato, este valor foi inserido na equação da reta obtida através da curva de calibração para Nitrato. O resultado foi multiplicado por 10 .

\section{5 - RESULTADOS E DISCUSSÃO}

A avaliação hidroquímica só foi capaz de ser efetuada tendo como base as principais legislações nacionais que tratam a qualidade da água, tais são:

- Resolução CONAMA n ${ }^{\circ}$ 357, de 17 de Março de 2005: Dispõe sobre a classificação dos corpos de água e diretrizes ambientais para o seu enquadramento, bem como estabelece as condições e padrões de lançamento de efluentes, e dá outras providências; 
- Resolução CONAMA n 396, de 3 de Abril de 2008: Dispõe sobre a classificação e diretrizes ambientais para o enquadramento das águas subterrâneas e dá outras providências;

- Portaria $\mathrm{n}^{\circ}$ 2.914, de 2 de Dezembro de 2011: Dispõe sobre os procedimentos de controle e de vigilância da qualidade da água para consumo humano e seu padrão de potabilidade.

A partir de tais valores de referência apresentados na Tabela 2, foi possível evoluir para uma avaliação da qualidade da água subterrânea à jusante do passivo ambiental, visando, sobre tudo, o consumo humano.

Tabela 2 - Padrões de referência para características físico-químicas das águas.

\begin{tabular}{|c|c|c|c|}
\hline PARÂMETROS & $\begin{array}{l}\text { CONAMA }^{1} \\
n^{\circ} 357 / 2005 \\
\end{array}$ & $\begin{array}{l}\text { CONAMA }^{2} \\
n^{\circ} 396 / 2008\end{array}$ & $\begin{array}{l}\text { PORTARIA } \\
n^{\circ} 2914 / 2011 \\
\end{array}$ \\
\hline $\mathrm{pH}$ & $6,0-9,0$ & - & $6,0-9,5$ \\
\hline $\mathrm{CE}\left(\mu \mathrm{S} . \mathrm{cm}^{-}{ }^{1}\right)$ & - & - & - \\
\hline Turbidez (UNT) & 40 & - & 5 \\
\hline Nitrito (mg. $\mathrm{L}^{-1}$ ) & 1 & 1 & 1 \\
\hline Nitrato $\left(\mathrm{mg} . \mathrm{L}^{-1}\right)$ & 10 & 10 & 10 \\
\hline Chumbo (mg.. $\left.{ }^{-1}\right)$ & 0,01 & 0,01 & 0,01 \\
\hline
\end{tabular}

Nota ${ }^{1}$ : Valores para enquadramento na Classe 1 de águas doce.

Nota2: Valores de Referência de Qualidade (VRQ) padrões para as Classes 1 e 2.

\section{$5.1-\mathbf{p H}$}

Na Tabela 3 estão apresentados os valores de $\mathrm{pH}$ das amostras coletadas nas datas de 04 de Outubro e 10 de Novembro de 2014, considerando os três poços de monitoramento e uma nascente próxima como referência de potabilidade.

Tabela 3 - Valores de $\mathrm{pH}$ referentes as duas datas de coleta.

\begin{tabular}{ccc}
\hline \multirow{2}{*}{ Pontos } & \multicolumn{2}{c}{$\mathbf{p H}$} \\
\cline { 2 - 3 } & 04/out $^{\mathbf{1}}$ & $\mathbf{1 0 / n o v}$ \\
\hline P1 & 6,04 & 7,83 \\
P2 & 5,78 & 6,85 \\
P3 & 5,94 & 6,70 \\
N & 6,45 & 7,46 \\
\hline
\end{tabular}

Nota ${ }^{1}$ : Valores medidos dois dias após a coleta.

Águas naturais possuem $\mathrm{pH}$ na faixa de 4 a 9, sendo ligeiramente básica, por causa de bicarbonato, carbonatos de metais alcalinos e alcalinos terrosos (CLESCERI et al., 1998). O pH é um parâmetro que para o consumo humano deve-se encontrar entre 6,5 a 9,5 segundo a legislação 
de água para consumo humano. A CONAMA n³57/2005, diz que a faixa deve ser entre 6 a 9. Na Portaria $\mathrm{n}^{\circ} 2914 / 2011$ deve ser 6 a 9,5 como padrão de potabilidade.

Assim, é possível observar pelos dados da Tabela 3, que todos os valores para $\mathrm{pH}$, exceto $\mathrm{P} 2 \mathrm{e}$ P3 de 04/out, se enquadram nos limites estabelecidos nas legislações. A diferença dos valores apresentados para P2 e P3 de 04/out pode-se dar pelo tempo para a medição deste parâmetro, que foi de 48 horas. Esta demora ocorreu devido ao fato, da coleta ter sido realizada no sábado dia 04/out e o laboratório estar disponível apenas na segunda-feira, 06/out, aliado a indisponibilidade do pHgâmetro portátil. De acordo com a normativa CETESB 6410 (1988) vários constituintes instáveis devem ser medidos in situ ou logo após a coleta, por exemplo, pH, devido a amostra apresentar volatilização de gases dissolvidos e compostos orgânicos que influenciam nas medidas.

\section{2 - CE - Condutividade Elétrica}

Sais dissolvidos e ionizados presentes na água transformam-na em um eletrólito capaz de conduzir a corrente elétrica. Depende das concentrações iônicas e da temperatura, indica a quantidade de sais existentes na coluna d'água e, portanto, representa uma medida indireta da concentração de poluentes. Em geral, níveis superiores a $100 \mu \mathrm{S} . \mathrm{cm}^{-1}$ indicam ambientes impactados (CETESB, 2014).

Sabendo disso e com base na Tabela 4 a seguir, podemos inferir que em todos os poços há um impacto significativo sobre as águas, exceto na nascente cujo valor está bem próximo ao limite para impacto.

Tabela 4 - Valores de Condutividade Elétrica referentes as duas datas de coleta.

\begin{tabular}{ccc}
\hline \multirow{2}{*}{ Pontos } & \multicolumn{2}{c}{ CE $\left(\boldsymbol{\mu S} . \mathbf{c m}^{-\mathbf{1}}\right)$} \\
\cline { 2 - 3 } & 04/out & $\mathbf{1 0 / n o v}$ \\
\hline P1 & 2059 & 2081 \\
P2 & 2359 & 2312 \\
P3 & 1098 & 1534 \\
N & 99,70 & 82,30 \\
\hline
\end{tabular}

A condutividade elétrica é uma propriedade que depende expressivamente da temperatura. Para propósitos comparativos de dados de CE, se definem temperaturas de referência de $20^{\circ} \mathrm{C}$ a $25^{\circ} \mathrm{C}$ (PINTO et al., 2007). Devido a isso, a CE da amostra do dia 04/out foi medida a uma temperatura de $20^{\circ} \mathrm{C}$ e a do dia $10 /$ nov a $24^{\circ} \mathrm{C}$.

Observando a Figura 7, a nascente é o único ponto livre de indícios de cargas contaminantes, apesar do valor medido no dia $04 /$ out estar bem próximo a $100 \mu \mathrm{S} . \mathrm{cm}^{-1}$, valor recomendado pela 
CETESB (2014). Todos os poços apresentaram valores maiores que $1000 \mu{\mathrm{S} . \mathrm{cm}^{-1}}^{-}$O poço P2, em ambas as datas, foi o que mais se destacou, mostrando alta presença de substâncias ionizantes dissolvidas na água comprovando contaminação pelo lixão.

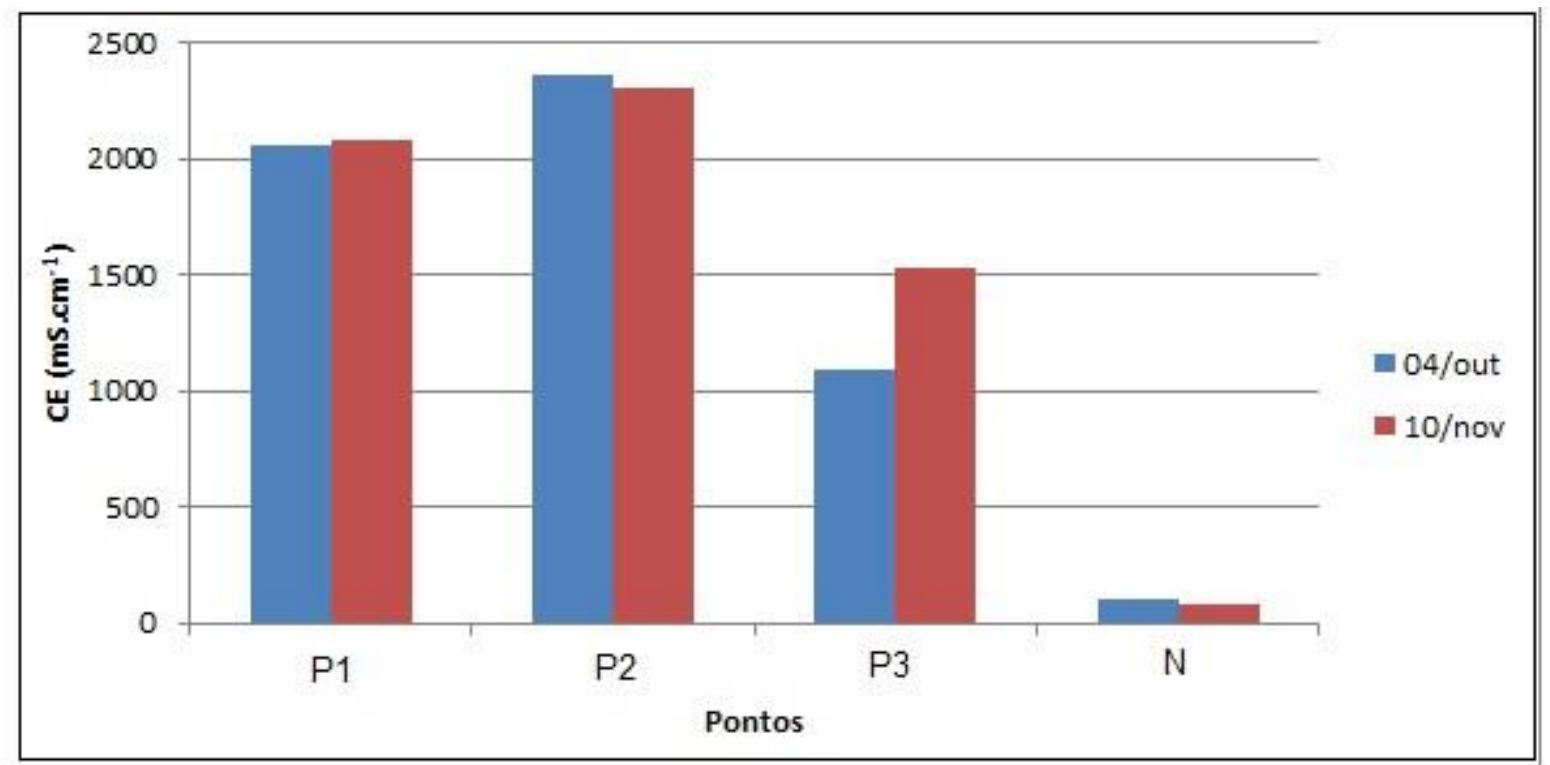

Figura 7 - Condutividade Elétrica nos pontos, com relação a data de medição.

\section{3 - Turbidez}

Sabendo que a turbidez mede a dificuldade de um feixe de luz ultrapassar certa quantidade de água, é causada por matérias sólidas em suspensão, por exemplo, silte, argila, colóides, matéria orgânica e microorganismos.

Águas subterrâneas normalmente não apresentam problemas devido ao excesso de turbidez, por isso, este parâmetro é limitado apenas pela Resolução CONAMA 357/2005 que classifica corpos d'água e trás o limite de 40 NTU.

A Tabela 5 apresenta os resultados obtidos deste parâmetro para os três poços e a nascente, medidos apenas na amostra coletada na data de 10/nov. Com isso, pode-se inferir que não houve divergências deste parâmetro em relação à potabilidade.

Tabela 5 - Valores de turbidez referentes aos três poços e a nascente.

\begin{tabular}{cc}
\hline Pontos & Turbidez (NTU) \\
\hline P1 & 1,68 \\
P2 & 1,54 \\
P3 & 10,8 \\
N & 1,73 \\
\hline
\end{tabular}


Observa-se que o valor de P3 se destacou, isso pode ter acontecido devido a movimentos bruscos no momento da coleta da amostra ocasionando o levantamento das partículas como o da argila, influenciando na turbidez.

\section{4 - Nitrito e Nitrato}

A Tabela 6 a seguir apresenta os valores encontrados para nitrito e nitrato.

Tabela 6 - Valores referentes ao nitrito e nitrato

\begin{tabular}{ccccc}
\hline \multirow{2}{*}{ Parâmetros $\left(\mathbf{m g . L}^{\mathbf{- 1}}\right)$} & \multicolumn{5}{c}{ Pontos } \\
\cline { 2 - 5 } & $\mathbf{P 1}$ & $\mathbf{P 2}$ & $\mathbf{P 3}$ & $\mathbf{N}$ \\
\hline Nitrito & 0,398 & 1,027 & 0,497 & 0,133 \\
Nitrato & 24,123 & 36,691 & 20,671 & 1,082 \\
\hline
\end{tabular}

Os valores de detecção do Nitrito se apresentam muito baixos, apesar do P2 apresentar valor maior que $1 \mathrm{mg} . \mathrm{L}^{-1}$ para padrão de potabilidade. Uma das hipóteses para a não detecção de valores altos para nitrito pode ser explicada pela rápida transformação destes a nitrato pelas bactérias Nitrobacter presentes no solo e pelo alto grau de mobilidade no nitrato no solo, se locomovendo rapidamente para as águas subterrâneas.

A Figura 8 a seguir, apresenta as isolinhas de concentração de nitrito ao longo dos pontos amostrados. Esta figura foi construída através da utilização do Software Surfer capaz de apresentar os níveis de concentração, por metodologia de interpolação, no espaço.

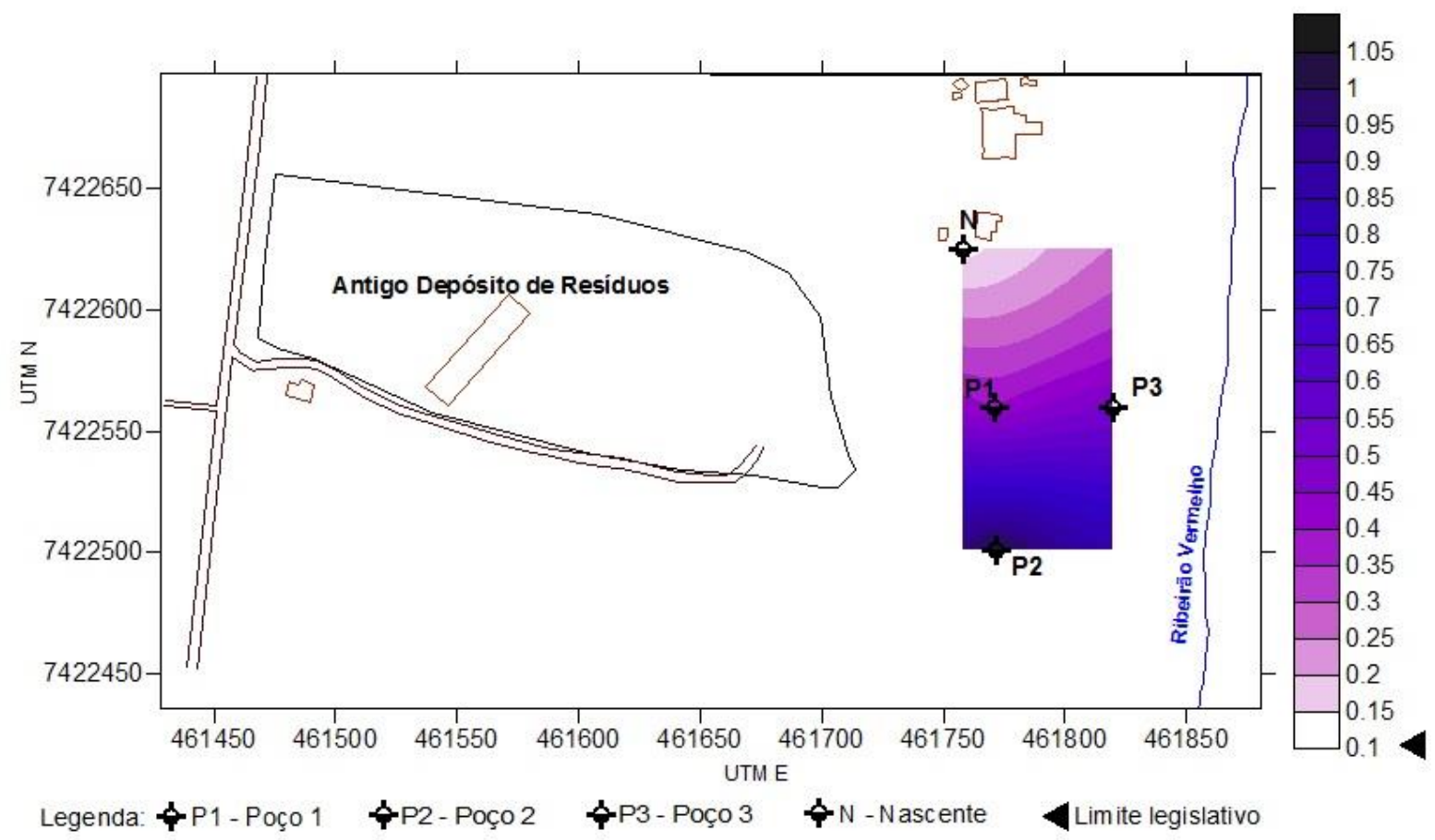

Figura 8 - Mapa indicativo de isolinhas de concentrações de Nitrito $\left(\mathrm{NO}_{2}\right)$ na área de estudo. 
O nitrato é um constituinte inorgânico nocivo à saúde que pode ser encontrado na água subterrânea. Devido a sua alta mobilidade e estabilidade química apresenta uma ocorrência problemática. Nas águas subterrâneas é comum a ocorrência de baixos teores de nitrato, pois é a substância presente no estágio final da degradação da matéria orgânica. Mas, as concentrações acima do valor de potabilidade torna-se um problema (FINEZA, 2008).

Pela Tabela 6, os valores de nitrato apresentam-se maiores que os padrões de potabilidade (10 mg. $\mathrm{L}^{-1}$ ) em todos os poços. Sendo o P2, representante do pior estado de contaminação por nitrato.

Através da Figura 9 é possível observar que as isolinhas de contaminação para o nitrato no aquífero à jusante da área estudada indicam que as maiores concentrações seguem exatamente o fluxo subterrâneo apresentando por Santos (2003), ou seja, partindo do ponto de maior potencial hidráulico, próximo às áreas de disposição final dos resíduos até o encerramento do lixão, a W (oeste) da área, para o sentido E (leste), em direção ao fluxo de base do ribeirão Vermelho, configurando assim em uma vasta pluma de contaminação.

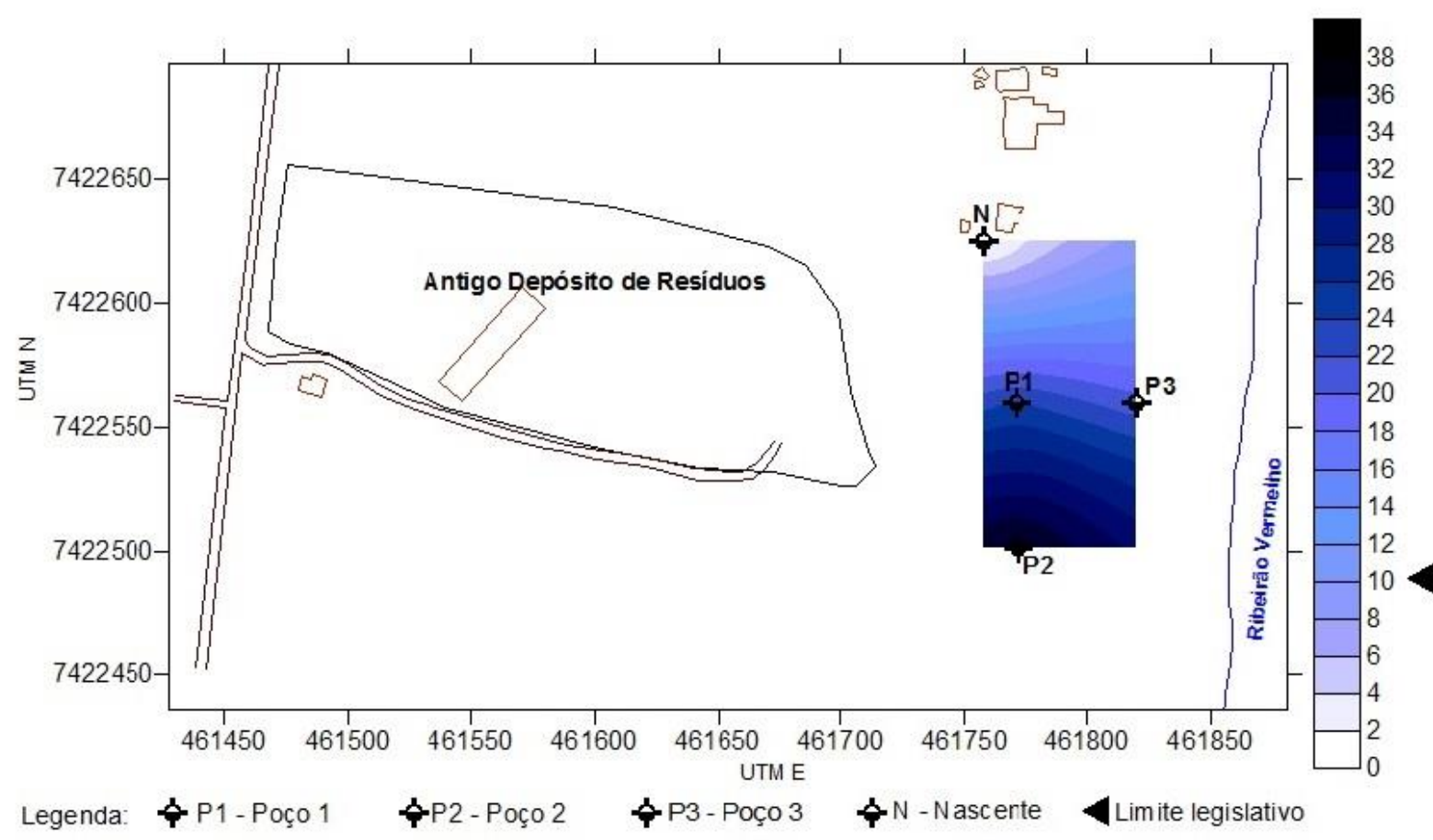

Figura 9 - Mapa indicativo de isolinhas de concentrações de Nitrato $\left(\mathrm{NO}_{3}\right)$ na área de estudo.

\section{5 - Chumbo}

As principais vias de exposição da população geral ao chumbo são oral e inalatória. Mais de $80 \%$ do chumbo que ingressa diariamente no organismo é oriundo da ingestão de alimentos, sujeiras e poeiras contendo o metal. O chumbo pode afetar quase todos os órgãos, sendo o sistema nervoso central mais sensível, tanto em crianças quanto em adultos (CETESB, 2012). 
Conforme Moreira; Moreira (2004), a interação do chumbo no organismo tem efeito acumulativo, afeta todos os órgãos e sistemas do organismo. Potencialmente têm o poder de inibir ou imitar a ação do cálcio e de interagir com proteínas, retido na maioria das vezes em ossos.

Segundo Andrade (2008), os compostos inorgânicos do chumbo (Pb) estão presentes em vários produtos da indústria e comércio, incluindo tintas, plásticos, baterias, ligas metálicas, inseticidas, cabos elétricos e cerâmicas. A maior parte desses produtos tem como destino final os lixões ou aterros.

Teixeira (2008) afirma que o comportamento do chumbo no chorume em áreas de disposição final de resíduos, tem relação direta com o $\mathrm{pH}$ do solo, conforme aumenta o $\mathrm{pH}$ do solo aumenta a retenção do chumbo no local. O transporte do chumbo do solo para águas subterrâneas por lixiviação é vagaroso em condições naturais, porém elevando a acidez do solo ou pela presença em concentrações que se aproximam ou excedam a capacidade de troca catiônica auxilia na percolação.

Fávaro (2014) obteve como resultado de seu trabalho, analisando chumbo no solo na área do antigo lixão de Rolândia, altos índices de contaminação (12,52 a 149,6 mg.Pb.kg-1 de solo) extrapolando, inclusive, os limites de concentração permissíveis das legislações específicas.

Com base nos resultados obtidos nos laudos das análises de água subterrânea apresentados na Tabela 10 a seguir, pode-se inferir que todos os poços extrapolam os limites dos padrões de potabilidade segundo as legislações atuais.

Tabela 1 - Quantidade de chumbo referentes às amostras de água subterrânea.

\begin{tabular}{cc}
\hline Pontos & Chumbo (mg. L $\left.^{-\mathbf{1}}\right)$ \\
\hline P1 & 0,04 \\
P2 & 0,02 \\
P3 & 0,03 \\
N & 0,00 \\
\hline
\end{tabular}

A Figura 10 apresenta as isolinhas de contaminação de chumbo para às águas subterrâneas à jusante da área estudada. É possível visualizar que as maiores contaminações seguem exatamente o fluxo subterrâneo definido por Santos (2003), cujo fluxo aquífero encerra-se na bacia do ribeirão Vermelho, consolidando assim um agravante desenho de pluma de contaminação. 


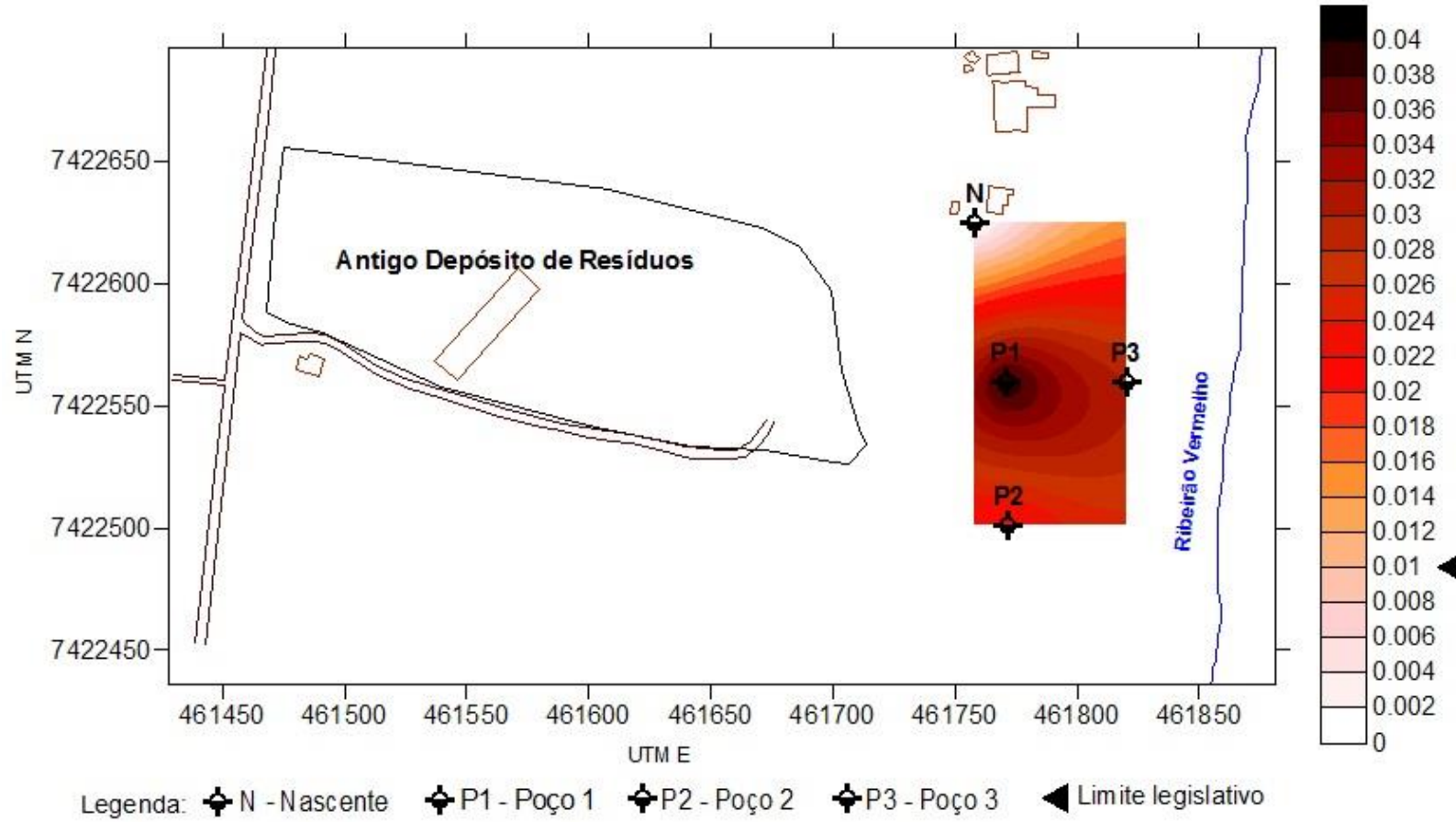

Figura 10 - Mapa indicativo das isolinhas de contaminação de chumbo na área do antigo lixão.

Santos (2002) em seu trabalho nestes mesmos pontos obteve valores preocupantes bem acima dos níveis aceitáveis: 0,165; 0,459 e 0,105 mg. $\mathrm{L}^{-1}$ para P1, P2 e P3, respectivamente. A Tabela 11, mostra os resultados obtidos desta pesquisa comparando-se aos valores encontrados por Santos (2002) e a porcentagem de redução da presença de chumbo na água subterrânea, após decorrido 12 anos. A redução expressiva da quantidade do chumbo pode ser dada em vista pela dissipação/dispersão e absorção pela vegetação instalada ao longo desse período.

Tabela 2 - Comparação e redução do chumbo após doze anos nas águas subterrâneas nos poços.

\begin{tabular}{cccc}
\hline & \multicolumn{2}{c}{ Chumbo (mg.L-1) } & Redução \\
\cline { 2 - 3 } Poços & Santos (2002) & $\begin{array}{c}\text { Betio } \\
(\mathbf{2 0 1 4})\end{array}$ & $\mathbf{( \% )}$ \\
\hline P1 & 0,165 & 0,04 & $75,76 \%$ \\
P2 & 0,459 & 0,02 & $95,64 \%$ \\
P3 & 0,105 & 0,03 & $71,43 \%$ \\
\hline
\end{tabular}

\section{6 - CONCLUSÃO}

Com relação às águas subterrâneas da região do antigo lixão de Rolândia - PR pode-se constatar:

- As condições de encerramento foram conduzidas de forma imprópria em relação à proteção ao meio ambiente local; 
- Visivelmente a área está recoberta com vegetação secundária, assim não é possível imaginar que há tantos efeitos adversos causados pelo lixão;

- Com relação ao parâmetro físico pH, os valores do dia 10/nov de forma geral, em todos pontos, apresentaram-se dentro dos padrões legislativos. Já os valores obtidos das amostras coletadas no dia 04/out apresentaram pequenas variações, esse fato possivelmente deu-se em decorrência da análise ter sido realizada dois dias após a coleta;

- O poço P2 se destacou como tendo os maiores valores de CE em ambas as datas. Todos os poços apresentaram presença de substâncias ionizantes dissolvidas comprovando contaminação significativa sobre a água. Inclusive, o ponto $\mathrm{N}$, se aproxima dos níveis de impacto;

- No item turbidez houve divergências deste parâmetro em relação à potabilidade em todos os poços de monitoramento;

- O nitrogênio apresenta-se em altos índices na forma de nitrato, por ter alta mobilidade e persistência no meio subterrâneo, foi encontrado em altas concentrações nas águas subterrâneas nos três poços de monitoramento investigados. O P2 foi o único que apresentou um valor maior que $1,00 \mathrm{mg} . \mathrm{L}^{-1}$ de nitrogênio na forma de nitrito, apesar do valor estar no limite de potabilidade.

- Com relação ao metal tóxico chumbo, todos os poços apresentaram valores em desconformidade com as legislações vigentes para potabilidade, com exceção da nascente de referência cuja presença não foi detectada.

De forma geral, conlui-se que há anomalias na qualidade da água, indicando ser imprópria para consumo, com exceção da nascente, que não sofreu interferência da pluma de contaminação do lixão.

A presente pesquisa mostrou que não bastam apenas legislações que visam somente à implantação de políticas para gestão e gerenciamento de resíduos sólidos. É necessário e de extrema importância planos efetivos de acompanhamento e de encerramento dos lixões.

Este estudo de caso mostra que o simples aterramento e abandono, há mais de dez anos, do antigo lixão de Rolândia - PR, não foi suficiente para sua recuperação natural. Pelo contrário, abandoná-lo ocasionou impactos ambientais que continuarão a se propagar por um longo período. Observa-se que desde a desativação não houve qualquer obra técnica para prevenção dos impactos provocados pela disposição inadequada dos resíduos sólidos, além da inexistência de qualquer monitoramento da área, que evite, por exemplo a exposição humana à contaminação.

Portanto, tendo em vista o tempo decorrido desde a data de desativação do lixão, está comprovado que o mesmo não possui autossuficiência para se regenerar naturalmente. Assim, vale a 
pena enfatizar a necessidade de estudos e ações ambientais para remediação e recuperação desta área degradada.

\section{7 - REFERÊNCIAS BIBLIOGRÁFICAS}

ANDRADE, M. G. Fitorremediação em Bioensaio Com Solos de Área de Mineração e Processamento de Chumbo, Avaliação Sob Diferentes Métodos de Extração. Dissertação (Mestrado) - Universidade Federal do Paraná, Curitiba, 2008;

APHA; AWWA \& WEF. Standard Methods for the examination of water and wastewater. 22. ed. Washington DC: 2012;

BRASIL. Portaria no 2.914, de 12 de Dezembro de 2011. Dispõe sobre os procedimentos de controle e de vigilância da qualidade da água para consumo humano e seu padrão de potabilidade. Brasília, 2011;

BRASIL. Resolução CONAMA n ${ }^{\circ} 396$, de 03 de Abril de 2008. Dispõe sobre a classificação e diretrizes ambientais para o enquadramento das águas subterrâneas e dá outras providências. Brasília, 2008;

BRASIL. Resolução CONAMA n ${ }^{\circ}$ 357, de 17 de Março de 2005. Dispõe sobre a classificação dos corpos de água e diretrizes ambientais para o seu enquadramento, bem como estabelece as condições e padrões de lançamento de efluentes, e dá outras providências. Brasília, 2005;

CELLIGOI, A.; SANTOS, M. M.; VIANA, T. R. Análise e interpretação do gradiente hidráulico do aqüífero freático em uma área na região sul de Londrina-PR. Geografia - Revista do Departamento de Geociências. UEL, v. 10, n. 1, p. 79-87, 2001;

CETESB. Águas Subterrâneas - Poluição das águas subterrâneas. São Paulo, 2014. Disponível em: 〈http://www.cetesb.sp.gov.br/agua/informacoes-basicas/3-poluicao-das-aguas-subterraneas〉. Acesso em 13 de nov. de 2014;

CETESB. Amostragem e monitoramento das águas subterrâneas: Norma CETESB, 1988. São Paulo, CETESB, 1999. 32p.;

CETESB. Chumbo e seus compostos. Ficha de Informação Toxicológica. São Paulo, 2012;

CETESB. Condutividade. 2014. Disponível em < http://www.cetesb.sp.gov.br/ userfiles/file/agua/aguas-superficiais/aguas-interiores/variaveis/aguas/variáveis _quimicas/condutividade.pdf $>$. Acesso em 28 de nov de 2014; 
CLESCERI, L.S.; GREENBERG,A.E.; EATON,A.D. Standar methods for the examination of water anda wastewater. 20th.ed. Washington,DC: American Public Health Association; American Water Works Association; Water Environment Federation, 1998.1325p.;

FAVARO, Bruna Lima. Avaliação Ambiental de Propriedades Químicas do Solo em Lixão Desativado do Município de Rolândia - PR. 2014. 87 p. Trabalho de Conclusão de Curso (Bacharelado em Engenharia Ambiental). - Universidade Tecnológica Federal do Paraná, Londrina 2014;

FINEZA, A. G. Avaliação da contaminação de águas subterrâneas por cemitérios: estudo de caso de Tabuleiro - MG. 2008, 54 p. Dissertação (Mestrado). Programa de Pós-Graduação em Engenharia Civil - Universidade Federal de Viçosa. Viçosa, 2008;

MILANI, E. J. Evolução tectono-estratigráfica da Bacia do Paraná e seu relacionamento com a geodinâmica fanerozóica do Gondwana Sul-Ocidental. 2 v. Tese (Doutorado) - Instituto de Geociências. Universidade Federal do Rio Grande do Sul, Porto Alegre, 1997.

MOREIRA, F. R.; MOREIRA, J. C. Os Efeitos do Chumbo Sobre o Organismo Humano e seu Significado para Saúde. Revista Panamericana de Salud Publica. V.15, n. 2, p. 199 - 129, 2004. PINTO, Magda C. F; DIAS, Denise L; PEREIRA, Edson J. Manual de Medição in loco:

Temperatura, pH, Condutividade Elétrica e Oxigênio Dissolvido. Serviço Geológico do Brasil, 2007. Disponível em < http://www.cprm.gov.br/pgagem /manual_medicoes_T_\%20pH_OD.pdf>. Acesso em 28 de nov 2014.

SANTOS, Maurício M. Avaliação do aquífero freático a jusante de um antigo depósito de resíduos em Rolândia-Pr. Trabalho de conclusão de curso (Bacharelado em Geografia) Departamento de Geografia, Universidade Estadual de Londrina, Londrina, 2003.

TEIXEIRA, R. S. Caracterização e Avaliação da Contaminação do Solo Laterítico da Área do Depósito de Resíduos Sólidos Urbanos de Londrina por Metais Pesados. Tese (Doutorado) Engenharia Civil, Universidade Federal de Santa Catarina, Florianópolis, Santa Catarina, 2008. 